\title{
Can the External Environment Generate Better Economic Performance in Academic Spin-Offs?
}

\author{
Ivano De Turi ${ }^{1,2} \&$ Margaret Antonicelli ${ }^{1,2}$ \\ ${ }^{1}$ Lum Jean Monnet University, Casamassima, Italy \\ ${ }^{2}$ Lum School of Management, Casamassima, Italy \\ Correspondence: Ivano De Turi, Lum Jean Monnet University, School of Management, Casamassima, Italy.
}

Received: August 30, 2019

doi:10.5539/ibr.v12n11p30

\begin{abstract}
The strategic stimulus to economic development is innovation. It was defined by Schumpeter as the commercial or industrial application of something new (product, process, production method). New product developments grew out of process innovation, particularly the development of components made from new materials, and the techniques to produce them the value of process innovation is proportional to the level of output produced by a given firm. Based on this we can distinguish two different life cycles: the life cycle of product technology and life cycle process technology. It's appropriate to understand if and how long these innovation processes lead to positive economic results. The innovation capabilities are the driver of long-term success. The relation should remain significant beyond short-term earnings or become even greater for earnings of a longer-term. The length of a firm's innovation cycle appears to be a determinant of the relationship between enhanced innovation capabilities and future earnings. The paper proposes a framework to evaluate the impact of academic spin-offs at the local level. Spin-off creation is the most complex way of commercializing academic research but has the highest potential impact on the local context. We develop a framework that takes into account the direct and indirect impacts of spin-offs. In the empirical part of the paper, we apply this framework to a sample of Italian spin-offs between 2001 and 2017. The empirical analysis shows that measured in quantitative terms, the impact of spin-offs on the local economy is quite small. Using the selected variables, It's possible to affirm that the presence of business incubators represents an element capable of positively influencing the performance of academic spin-offs.
\end{abstract}

Keywords: innovation, entrepreneurship, technology transfer, econometric approach, panel model, academic spin-off

\section{Introduction}

In the last decade, there has been growing attention of the institutions towards the third mission of Universities. The university, along with their two fundamental goals of education and research, pursues a 'third mission', which means that it works to encourage the direct application, enhancement and use of learning to contribute to society's social, cultural and economic development. An instrument to pursue this mission is the creation by universities of academic spin-offs (ASOs) transferring the research results to the business world. The inventions resulting from the scientific research of the universities and transferred to the business world through the creation of new companies (academic spin-offs) represents one of the opportunities for wealth creation that starts from the results of the research. Students, researchers and professors during their university experience acquire scientific knowledge and can develop new technologies that, in the future, could be used to implement the university's internal structures (business incubators, technology parks, business accelerators) or to create a new product to be tested in the business world by creating a new academic spin-off. This paper aims to evaluate the impact of the external environment on the economic performance of Italian academic spin-offs. The theoretical structure, on which the relationship between logical and linear variables is based, can be summarized by the graphic representation that follows. 


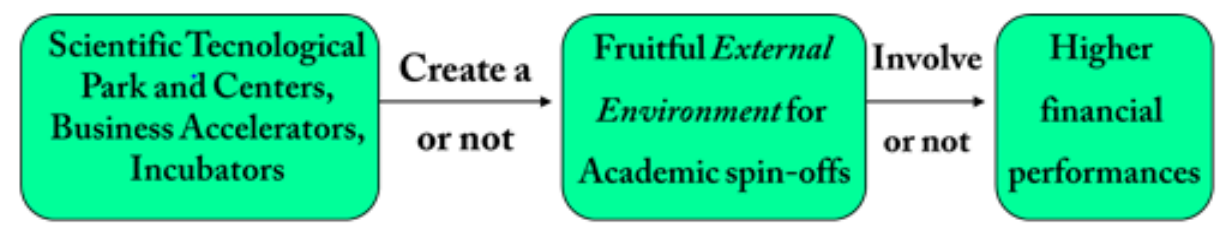

Figure 1. Theoretical framework (De Turi, Garzoni, 2018)

The external environment has always given a central role in the theory of entrepreneurship. By external environment, we mean all the forces and elements outside the boundaries of the organization that directly or indirectly influence or are influenced by the choices of the organizations, as well as by technological, socio-cultural and economic forces that constitute the broader context within the organization operates. Several scholars have emphasized, in their research, how inseparable was the external environment from the entrepreneurial process. In this sense, it is easy to understand how much particular environmental conditions can encourage as well as hinder entrepreneurial activity. The fiscal and regulatory impact, as well as the political-legal forces, play a fundamental role in the generation of positive business results. At the international level, in recent years, the growth of the number of new science-based companies has turned out to be much higher in positive environmental contexts. In a period of knowledge-based competition, the processes of technological transfer from the university research to the business world play a central role in the competitiveness of nations and regions. After a literature review of publications concerning the centrality of the external environment in the context of company performance, it emerged that the elements of the external environment most taken into consideration by academics are: Regional and local context, University level, Networks, Technology transfer office and Business Incubators. For this work, we decided to use the presence or absence in the province of business incubators, business accelerators and technology parks as control variables. Instead, for the academic spin-offs growth indicators several publications have been examined in that field (Davidsson et al. 2005, Zhang 2008, Zhou et al. 2010, Salvador 2010, Wennberg et al. 2011, Criaco et al. 2014, Agostini et al. 2014, Novotny 2014, Galati et al. 2016). From the literature review concerning the identification of the most suitable indicators to evaluate growth, the most used is sales. Compared to all the authors mentioned above, except for Zhang, everyone used sales as a variable dedicated to analyzing the growth of academic spin-offs, and we, therefore, consider using the same in this work as well.

\section{Literature Review}

In an era of knowledge-based competition, technology transfer from university to firms is a key issue of the wealth of nations and regions (De Turi, Garzoni 2014). The creation of academic spin-offs is one of the ways through which such a technology transfer process (TTP) can be pursued. Although in Italy this form of TTP has become more and more popular in recent years (Netval 2008), the gap compared with other EU countries remains significant (Parente, Feola, 2013). In this section, it is appropriate to highlight how researchers analyzed the performance of academic spin-offs, in the recent past, and what were the most influential indicators of the external environment. The most widely used growth indicator is Sales (Davidsson et al., 2005; Zhou et al., 2010, Salvador, 2010; Wennberg et al., 2011; Criaco et al., 2014; Agostini et al., 2014; Novotny, 2014; Galati et al., 2016), following there is Employment (Davidsson et al., 2005; Zhang, 2008; Zhou et al., 2010, Wennberg et al., 2011; Criaco et al., 2014; Novotny, 2014; Galati et al. , 2016). Instead, as regards the role External environment, the most influencer external factor is the regional and local context (Zhang, 2008; Fini et al., 2011; Meoli and Vismara, 2016; Galati et al., 2016) following the presence of Incubator/ Science park/ Accelerator (Davenport et al., 2002; Zhang, 2008; Soetanto and Jack, 2016). By this literature review emerged that the growth indicators more suitable for assessing the academic spin-offs appear to be 'Sales' and Employment' and they are strongly influenced by the 'Regional/local context' and "Incubator/ Science park/ Accelerator".

\section{Method}

The main objectives of this research work are, in the first analysis, to identify the exact constraints of the independent variables on the sales of italian's ASO's. In order to test the set up hypotheses, a random regression model has been performed. The panel data scrutiny has a benefit of covering the info essential to the arrangement with both the intertemporal dynamics and independence of the units being inspected (Riaz N, Riaz S., 2018). Panel data from 1981 to 2017 for 1762 italian's ASO's has been taken by AIDA Bureau Van Dijk. 


\subsection{Model Specification}

The study identifies the impact of financial performances and external environment roles on sales italian's ASO's. The panel data scrutiny as it has a benefit of covering the info essential to the arrangement with both the intertemporal dynamics and independence of the units being inspected.

The model takes both the cross-section dimension and the time-series dimension into consideration. In line with this, a test for heteroskedasticity is conducted using the Breusch-Pagan test. This test checks whether the estimated variance on the residuals of the regression model depends on one of the independent variables. The null hypothesis of this test is the presence of homoschedasticity, while the hypothesis alternative is the presence of heteroskedasticity. The results obtained show an o-value equal to 0,7371 , then I accept the null hypothesis of residual homoschedasticity. It, therefore, seems that the doubts concerning the homoschedasticity given by a strong temporal instability of the analyzed variables are raised. After performing the Breusch-Pagan test and obtaining indications of homoschedasticity of residues, I carry out for further confirmation of actual homoschedasticity also the White test.

In this case, regarding the null hypothesis of homoschedasticity, this is accepted respectively at the levels of significance of $1 \%$ and $10 \%$, respectively. In this case, there is evidence of homoschedasticity in which the error variance constant. In the second step, a test for serial correlation for error terms is conducted using the Wooldridge test for autocorrelation in panel data, the result yields a p-value of 0.0151 , which implies there is evidence of serial correlation (first-order autocorrelation) and hence, the error terms are correlated. Moreover, though the stationary test for panel data is a recent phenomenon, this study employs the Levin-Lin-Chu test for stationarity and confirms that the nullhypothesis of non-stationarity is rejected at the $1 \%$ significance level, i.e. the data is stable with a constant mean, variance and standard error. A specification test is conducted to determine which estimation methods would be more appropriate for this particular study. According to Gujarati (2003), there is a formal test called the 'Hausman test' that helps to choose between fixed effect model (FEM) and the random effect model (REM).

Evaluating a Prob $>$ chi2 value $^{1}=0.1104$, it is possible to declare that the Random Effects model is fit as is indicated by the probability value of Hausman test.

A simple formulation of Random Effects model is:

$$
\mathrm{Y}_{\mathrm{i}, \mathrm{t}}=\beta \mathrm{X}_{\mathrm{it}-1}+\alpha+\mathrm{u}_{\mathrm{it}}-1+\mathrm{e}_{\mathrm{it}-1}
$$

In this analysis, run the Random Effects model first as it is accommodated with an advantage of assuming that an individual entities error term is uncorrelated with the regressor which qualifies the time invariant variables to be treated as predictors. However, engrossed with some bias, it is tedious to choose among fixed or random effects model at random. Thus, the Hausmann test declares the model fit for the analysis. The Hausman test testifies whether the unique errors are correlated with the regressors or not (Rahaman N., Rahaman M. N., 2018).

Regarding the specific formulation of Random Effects model, it has:

$$
\operatorname{LnSALES}_{\mathrm{it}}=\beta_{0 \mathrm{i}, \mathrm{t}-1}+\beta_{1 \mathrm{i}, \mathrm{t}-1} \operatorname{LnAGE}+\beta_{2 \mathrm{i}, \mathrm{t}-1} \operatorname{LnAS}+\beta_{3 \mathrm{i}, \mathrm{t}-1} \mathrm{EM}+\beta_{4 \mathrm{i}, \mathrm{t}-1} \mathrm{LF}+\beta_{5 \mathrm{i}, \mathrm{t}-1} \mathrm{STPC}+\beta_{6 \mathrm{i}, \mathrm{t}-1} \mathrm{BA}+\beta_{7 \mathrm{i}, \mathrm{t}-1} \mathrm{IN}+\varepsilon_{\mathrm{it}-1}
$$

where:

- LnSALES is the natural logarithm of sales of the sample;

- $\quad \beta_{0}$ is the constant, $\beta$ are the variable coefficients;

- LnAGE is the natural logarithm of the total number of days between the date of creation of the ASO's

and December 31th 2017;

1 The Hausman test hypotesys are:

$\mathrm{b}=$ consistent under Ho and $\mathrm{Ha}$; obtained from xtreg;

$\mathrm{B}=$ inconsistent under Ha, efficient under Ho; obtained from xtreg

Test: Ho: difference in coefficients not systematic $-\operatorname{chi} 2(2)=\operatorname{Prob}>\operatorname{chi} 2=0.1104$ 
- LnAS is the natural logarithm of the total asset; it refers to the total amount of assets owned by a firm;

- $\quad$ EM is the EBITDA margin, obtained dividing EBITDA by total sales; this result helps show how much operating expenses are eating into a company's profits.

- LF is a dummy variable that represents the legal form of the ASO (1 if is S.r.l. and 0 if is S.p.a.);

- $\quad$ STPC is a dummy variable that represents the presence (1) or not (0), in the province of the legal address of the ASO, of a Scientific/Technological Park or Center;

- $\quad$ BA is a dummy variable that represents the presence (1) or not (0), in the province of the legal address of the ASO, of a Business Accelerator;

- IN is a dummy variable that represents the presence (1) or not (0), in the province of the legal address of the ASO, of an Incubator;

It uses the natural logarithm of total sales (LnSALES) as dependent variable as Wennberg et al. (2011) that estimated a model for growth in terms of sales using the formula log (size1/size0) to compute the growth rate. In this paper, it estimated a model for growth using the formula log to obtain as result the effect, in percentage, on Y of a change in independent variable, holding all the other variables constant. The percentage change in $\mathrm{Y}$ is equal to $(100 * \Delta \mathrm{Y} / \mathrm{Y})$; a change in $\mathrm{X}$ by one unit $(\Delta \mathrm{X}=1)$ is associated with a $100 * \beta 1 \%$ change in $\mathrm{Y}$ (Stock \& Watson, 2005). The logarithm also has the advantage to transform the sales value in a smaller number easier to use. This is the case of a "log-linear" function because just the dependent variable (and none of independent variables) is a natural logarithm.

The control variables used, pursuant to the most relevant literature (Rodriguez et al., 2016), are the following:

1. Ln of Age (LnAge)

2. Ln of Total assets (LnAS);

3. $\quad$ EBITDA margin (EM);

4. Legal form (LF).

The external environment variables (STPC, BA and IN) are the three variables that It analyses with the aim to understand if, and to what extent, there is a relationship (positive or negative but especially statistically significant) able to influence the ASO's Sales.

In addition to the independent and control and, in both functions there are:

$-\mu \mathrm{i}$ e $\eta \mathrm{t}$, that represent fixed effects respectively of enterprise and temporal ones;

- ei,t-1 that is an independent and identically distributed disorder.

\section{Results}

\subsection{Statistics and Data Analysis}

The Random Effects Model is run to gauge, primarily, the impact of financial performances and external environment roles on sales italian's ASO's. The general model was found valid without statistical problems. Table 1 reports the descriptive statistics for the mean and standard deviation, while Table 2 regards correlation values associated with the study variables. 
Table 1. Descriptive statistics

\begin{tabular}{|c|c|c|c|}
\hline Variable & & Mean & Std. Dev. \\
\hline \multirow[t]{3}{*}{ LnSA } & Overall & 5,0113 & 1,5716 \\
\hline & Between & & 4,3477 \\
\hline & Within & & 1,0187 \\
\hline \multirow[t]{3}{*}{ LnAGE } & Overall & 7,8214 & 0,8976 \\
\hline & Between & & 2,7234 \\
\hline & Within & & 0,5413 \\
\hline \multirow[t]{3}{*}{ LnAS } & Overall & 5,4519 & 1,5816 \\
\hline & Between & & 3,0184 \\
\hline & Within & & 1,0137 \\
\hline \multirow[t]{3}{*}{ EM } & Overall & 0,2372 & 1,4316 \\
\hline & Between & & 3,2143 \\
\hline & Within & & 1,1349 \\
\hline \multirow[t]{3}{*}{$\mathrm{LF}$} & Overall & 1,1243 & 0,3246 \\
\hline & Between & & 2,6547 \\
\hline & Within & & 0,3004 \\
\hline \multirow[t]{3}{*}{ STPC } & Overall & 0,6935 & 0,6606 \\
\hline & Between & & 1,9173 \\
\hline & Within & & 0,5791 \\
\hline \multirow[t]{3}{*}{ BA } & Overall & 0,7132 & 0,6606 \\
\hline & Between & & 3,7985 \\
\hline & Within & & 0,6585 \\
\hline \multirow[t]{3}{*}{ IN } & Overall & 0,6853 & 0,6517 \\
\hline & Between & & 2,8743 \\
\hline & Within & & 0,3488 \\
\hline
\end{tabular}

As regards descriptive statistics, all the indicators have been calculated following the panel setting of the dataset. In fact, the three types of analysis are present: overall, between and within. As it follows from the analysis, the low dispersion values are confirmation of the lack of outliers. Thus, the analyzed sample doesn't show any kind of anomalies.

Table 2 shows correlation matrix, in accordance with what was stated in our research hypotheses, most estimated correlation coefficients is significant under 5\% significant level.

Apart from the high direct correlation level between natural logarithm of the total asset and natural logarithm of sales $(0,7480)$, there are highest and statistically significant squared term of correlation.

However, consistent with existing literature these values are acceptable in terms of possible multi-collinearity concerns.

To avoid problems of this kind, accurate tests have been carried out which they have anyway confirmed the absence of multi-collinearity problems.

Table 2. Correlation matrix

\begin{tabular}{lcccccccc}
\hline & LNSA & LNAGE & LNAS & LF & EM & SCPC & BA & IN \\
\hline LNSA & $\mathbf{1 , 0 0}$ & & & & & & & \\
LNAGE & 0,5131 & $\mathbf{1 , 0 0}$ & & & & & & \\
& 0,0000 & & & & & & & \\
LNAS & 0,7480 & 0,5678 & $\mathbf{1 , 0 0}$ & & & & & \\
& 0,0000 & 0,0000 & & & & & & \\
LF & $-0,3017$ & $-0,1315$ & $-0,3716$ & $\mathbf{1 , 0 0}$ & & & & \\
& 0,0000 & 0,0000 & 0,0000 & & & & & \\
EM & $-0,0610$ & $-0,0372$ & $-0,1321$ & 0,2319 & $\mathbf{1 , 0 0}$ & & & \\
& 0,2197 & 0,3887 & 0,0021 & 0,0000 & & & & \\
SCPC & $-0,0272$ & $-0,0364$ & 0,0207 & 0,0719 & 0,0617 & $\mathbf{1 , 0 0}$ & & \\
& 0,5571 & 0,3901 & 0,7399 & 0,1087 & 0,2107 & & & \\
BA & 0,1079 & 0,1813 & 0,1497 & $-0,0601$ & $-0,0139$ & 0,1609 & $\mathbf{1 , 0 0}$ & \\
& 0,0149 & 0,0073 & 0,0006 & 0,1734 & 0,7299 & 0,0000 & & \\
IN & 0,1274 & $-0,0138$ & 0,0996 & $-0,0671$ & $-0,0189$ & $-0,2045$ & 0,1032 & $\mathbf{1 , 0 0}$ \\
& 0,0021 & 0,7301 & 0,0313 & 0,1190 & 0,8017 & 0,0097 & 0,0249 & \\
\hline
\end{tabular}

As already underlined, the highest correlation coefficient concerns the relationship between the natural logarithm of sales and the natural logarithm of total assets (0.748), demonstrating that the size of the company in a 
determining factor to improve financial performance.

Regarding to the result of the correlation matrix, we can affirm that the presence in the province of the legal address of the ASO of an Incubator is positively related to the natural logarithm of Sales $(0,13)$. Contemplating probably the fact that most of the firms with localized "near" an Incubator could be able to achieve better financial performance than others could.

We report the results of the random effect model analyses in Table 3.

Table 3. Random effect GLS model - dependent variable: FDI

\begin{tabular}{lrrrr}
\hline \multicolumn{1}{c}{ LnSA } & Coef. & Std. Err. & T & p-value \\
\hline LnAGE & 0,64 & 0,26 & 2,462 & 0,002 \\
LnAS & 0,64 & 0,041 & 15,610 & 0,012 \\
LF & $-0,13$ & 0,19 & $-0,684$ & 0.657 \\
EM & 0,06 & 0,033 & 1,818 & 0,007 \\
SCPC & $-0,08$ & 0,09 & $-0,889$ & $-0,889$ \\
BA & $-0,009$ & 0,082 & 2,462 & $-0,110$ \\
IN & 0,23 & 0,12 & 15,610 & $-0,098$ \\
cons & $-0,09$ & 0,91 & $-0,099$ & \\
\hline sigma_u & 0,0579 & & & (fraction of variance due to u_i) \\
sigma_e & 0,5013 & & & \\
rho & 0,0327 & within & 0,2107 &
\end{tabular}

$* * *$ significance at $1 \%$ level, ** significance at $5 \%$ level, * significance at $10 \%$ level

\subsection{Discussion}

The regressors of this model explain more than $20 \%$ of the variance; in fact, analyzing the results of the R-sq overall, between and within, these record values equal to $0,2468,0,3579$ and 0,2107 . Regarding to the three dummy variables, the presence ì in the province of the legal address of the ASO, of a Scientific/Technological Park or Center (SCPC) and the presence in the province of the legal address of the ASO, of a Business Accelerator (BA) result not statistically significant, with a p-value equal to $-0,110$ and $-0,098$. Conversely, instead, the results, as regards the link between the presence in the province of an incubator's legal address of the ASO and sales, seem to demonstrate the existence of a positive relationship and that this link is statistically significant (De Turi, Garzoni, 2018). The best financial performance, in terms of sales, characterized the companies located "near" an incubator. Analyzing, subsequently, the control variables (LnAge, LnAS and EM), it is possible to affirm that they are statistically significant at the level of $1 \%$ or $5 \%$, with p-value respectively equal to $0,002,0,012$ and 0,007 .

\section{Conclusions and Limitation}

According to the results of the analysis of the selected variables, it emerged that the presence of business incubators represents an element capable of positively influencing the performance of academic spin-offs. This was also confirmed by interviews with members of some academic spin-offs located near an incubator. According to them, this provides a constant element of growth and exchange that is at the base of all innovation processes. Other researchers have tested these variables in the past with simpler models (OLS) and the result emerged was the same (De Turi, Garzoni, 2018). This to further confirm the validity of the emerged evidences. As far as the limit of this research is given by the use of a static analysis. We could evaluate the possibility to introduce an instrumental variable with which to integrate the model, conseguently perform a dynamic panel (GMM). Furthermore, another interesting approach to be used to analyze this topic is the use of a factorial analysis to better define the determinants of the phenomenon being treated.

\section{References}

Agostini, L., Filippini, R., \& Nosella, A. (2016). Protecting intellectual property to enhance firm performance: does it work for SMEs \& quest. Knowledge Management Research \& Practice, 14(1), 96-105. https://doi.org/10.1057/kmrp.2014.20

Algieri, B., Aquino, A., \& Succurro, M. (2013). Technology transfer offices and academic spin-off creation: the case of Italy. Journal of Technology Transfer, 38, 382. https://doi.org/10.1007/s10961-011-9241-8 
Badea, L., Panait, I., Socol A., \& Moraru A. D. (2018). Economic Computation \& Economic Cybernetics Studies \& Research, 52(2), 69-85. https://doi.org/10.24818/18423264/52.3.18.06

Borges, C., \& Filion, L. J. (2013). Spin-off Process and the Development of Academic Entrepreneur's Social Capital. J.Technol. Manag. Innov, 8(1). https://doi.org/10.4067/S0718-27242013000100003

Bruno, A., \& Tyebjee, T. (1982). Developing the Marketing Concept in Public Accounting. Journal of the Academy of Marketing Science, 10, 165. https://doi.org/10.1007/BF02721906

Carayannis, E., Rogers, E., Kuriharac, K., \& Allbritton, M. (1998). High-technology spinoffs from government R\&D laboratories and research universities. Technovation, 1-11. https://doi.org/10.1016/S0166-4972(97)00101-6

Clarysse, B., Wright, M., Lockett, A., Van de Velde, E., \& Vohora, A. (2005). Spinning out new ventures: A typology of incubation strategies from European research institutions. Journal of Business Venturing, 183-216. https://doi.org/10.1016/j.jbusvent.2003.12.004

Covin, J. G., \& Slevin, D. P. (1991). A Conceptual Model of Entrepreneurship as Firm Behavior. Entrepreneurship Theory and Practice, 16(1), 7-25. https://doi.org/10.1177/104225879101600102

Criaco, G., Minola, T., Serarols, C., \& Bhatiya, A. (2013). Companies Spun Out of Universities: Different Typologies for Different Performance Patterns. Handbook of Research on Techno-Entrepreneurship, 2. Retrieved from https://ssrn.com/abstract=2346976

Davidsson, P., Achtenhagen, L., \& Naldi, L. (2005). Research on small firm growth: A review. Paper presented at the 35th EISB Conference. Barcelona, Spain. Retrieved from http://citeseerx.ist.psu.edu/viewdoc/download?doi=10.1.1.573.4282\&rep=rep1\&type=pdf

De Turi, I., \& Garzoni, A. (2014). The role of academic spin offs in entrepreneurial innovation and regional development: the Apulia case. European Journal of Economics and Management, 2(2). Retrieved from http://www.ejemjournal.com/EJEM_2015_Vol.2_No.2-SPECIAL_ISSUE.pdf

De Turi, I., \& Garzoni, A. (2018). The Impact of the External Environment on the Growth of the Italian Academic Spin-Offs: A Cross-Sectional Analysis. International Journal of Business and Management, 13(8). https://doi.org/10.5539/ijbm.v13n8p16

Festel, G. (2015). Technology transfer models based on academic spin-offs within the industrial biotechnology sector. International Journal of Innovation Management, 19(4), 134-137. https://doi.org/10.1142/S1363919615500310

Florentina, C. (2013). Regional Development and Innovation In Romania. Challenges and Perspectives. Annals of Faculty of Economics, 234-242. Retrieved from http://anale.steconomiceuoradea.ro/volume/2013/n1/025.pdf

Galati, F., Bigliardi, B., Petroni, A., \& Marolla, G. (2016). Which factors are perceived as obstacles for the growth of Italian academic spin-offs? Technology Analysis \& Strategic Management, 29(1), 84-104. https://doi.org/10.1080/09537325.2016.1199853

Green Paper, European Commission. (2008). Retrieved from http://ec.europa.eu/internal_market/copyright/docs/copyright-infso/greenpaper_en.pdf

Kent, C. (1984). The Environment for Entrepreneurship. Sloan Management Review.

Lazzeroni, M., \& Piccaluga, A. (2003). Towards the Entrepreneurial University. Local Economy. https://doi.org/10.1080/0269094032000073807

Lipton, M., \& Lorsch, J. W. (1992). A modest proposal for improved corporate governance. Business Lawyer, 48(1), 59-77. https://doi.org/10.12691/jfa-2-4-2

Lockett, A., Siegel, D., Wright, M., \& Ensley, M. D. (2005). The creation of spin-off firms at public research institutions: Managerial and policy implications. Research Policy, 981-993. https://doi.org/10.1016/j.respol.2005.05.010

Markman, G., Phan, H., Balkin, D., \& Gianiodis, P. (2005). Entrepreneurship and university-based technology transfer. Journal of Business Venturing, 20(2), 241-263. https://doi.org/10.1016/j.jbusvent.2003.12.003

Mueller, P. (2006). Exploring the knowledge filter: How entrepreneurship and university-industry relationships drive economic growth. Research Policy, 1499-1508. https://doi.org/10.1016/j.respol.2006.09.023

Netval. (2008). Annual Report. Retrieved from 
https://netval.it/static/media/uploads/files/20090507_Rapporto_Netval_2008.pdf

Novotny, A. (2014). Motivation and Success of Academic Spin-Offs; Evidence from Hungary. The Annals of the University of Oradea, 23, 1212-1219. Retrieved from http://steconomiceuoradea.ro/anale/volume/2014/n1/135.pdf

Parente, R., \& Feola, R. (2013). Entrepreneurial intent and entrepreneurial commitment of young researchers. International Journal of Technology Management \& Sustainable Development, 12(2). http://dx.doi.org/10.1386/tmsd.12.2.155_1

Quetglas, G. M., \& Grau, B. G. (2002). Aspects of University Research and Technology Transfer to Private Industry. Journal of Business Ethics, 39(1), 51-58. https://doi.org/10.1023/A:1016375832641

Rodríguez-Gulías, M., Fernández-López, S., \& Rodeiro-Pazos, D. (2016). Growth determinants in entrepreneurship: A longitudinal study of Spanish technology-based university spin-offs. Journal of International Entrepreneurship, 14(3), 323-344. https://doi.org/10.1007/s10843-016-0185-9

Salvador, E. (2010). How effective are research spin-off firms in Italy? Rev Écon Ind., 99-122. https://doi.org/10.4000/rei.4972

Siegel, D. S., Waldman, D., \& Link, A. (2003). Assessing the impact of organizational practices on the relative productivity of university technology transfer offices: An exploratory study. Research Policy, 27-48. https://doi.org/10.1016/S0048-7333(01)00196-2

Soetanto, D., \& Jack, S. (2016). The impact of university-based incubation support on the innovation strategy of academic spin-offs. Technovation, 50(51), 25-40. https://doi.org/10.1016/j.technovation.2015.11.001

Stock, J. H., \& Watson, M. W. (2005). Implications of Dynamic Factor Models for VAR Analysis. Harvard University. https://doi.org/10.3386/w11467

Vohora, A., Wright, M., \& Lockett, A. (2004). Critical junctures in the growth in university high-tech spinout companies. Research Policy, 147-175. https://doi.org/10.1299/jsmeicbtt.2002.1.0_12

Wennberg, K., Wiklund, J., \& Wright, M. (2011). The effectiveness of university knowledge spillovers: Performance differences between university spinoffs and corporate spinoffs. Research Policy, 40(8), 1128-1143. https://doi.org/10.1016/j.respol.2011.05.014

Zhang, J. (2009). The performance of university spin-offs: an exploratory analysis using venture capital data. The Journal of Technology Transfer, 34(3), 255-285. https://doi.org/10.1007/s10961-008-9088-9

Zhou, Y., T., \& Minshall, et al. (2010). Building Innovation Capabilities: An Inquiry into the Dynamic Growth Process of University Spin-outs in China. Int. J. Innovation and Technology Management, 7(3), 273-302. https://doi.org/10.1142/S0219877010002082

\section{Copyrights}

Copyright for this article is retained by the author(s), with first publication rights granted to the journal.

This is an open-access article distributed under the terms and conditions of the Creative Commons Attribution license (http://creativecommons.org/licenses/by/4.0/). 